4 Eduardo Viveiros de Castro, Araweté: os deuses canibais, Rio de Janeiro, Zahar/Anpocs, 1986; From the enemy's point of view: humanity and divinity in na Amazonian society, Chicago, University of Chicago Press, 1992.

5 Emmanuel Désveaux, Quadratura americana: essai d'anthropologie lévi-straussienne, Genebra, Georg Editeur, 2001, p. 229.

6 Eduardo Viveiros de Castro, "O campo na selva, visto da praia”. Estudos Históricos, 5/10, 1992, pp. 170-190.

7 Não se trata aqui da distinção que se tornou comum no Brasil, ou seja, da etnologia indígena, de um lado, e outras antropologias (urbana, rural, da religião etc.), de outro. Pelo contrário, frisa-se que esse é um exercício de antropologia em sua plenitude, como poderiam ser outros, cujos dados "etnográficos" não são propriamente "étnicos" ou indígenas. Lévi-Strauss comenta essa distinção gradativa e assinala que essas podem ser "três fases de uma mesma pesquisa", diferenciando-se pelo distanciamento que se toma dos dados particulares e pelo escopo da generalização. Cf. Antropologia estrutural I, Rio de Janeiro, Tempo Brasileiro, 1975, pp. 394-396.

8 Claude Lévi-Strauss, História de Lince, São Paulo, Companhia das Letras, 1991.

CLARICE COHN é doutoranda no Departamento de Antropologia da Faculdade de Filosofia, Letras e Ciências Humanas da USP e bolsista do CNPq.

\section{Tupi-guarani, um caso de fidelidade}

Carlos FAUSTO. Inimigos fiéis: história, guerra e xamanismo na Amazônia. São Paulo, Edusp, 2001. 587 páginas.

João Dal Poz

A etnologia das sociedades indígenas sulamericanas, nas últimas décadas, trouxe resultados bastante promissores. As descrições etnográficas, no entanto, distribuem-se ainda de maneira desigual, em extensão e densidade, o que se deve creditar a um pouco orquestrado, se não disperso moto investigativo. Os percalços, não resta dúvida, são variados e nada irrelevantes. Todavia, alguns esforços continuados sobressaem, graças ao empenho de sucessivas gerações de antropólogos.

A copiosa tradição de estudos acerca dos povos da família lingüística tupi-guarani, o ramo principal do tronco tupi, é um dos casos mais exemplares. Aos trabalhos pioneiros de Curt Nimuendaju (1914) entre os Apapokuva, no Brasil, e de Leon Cadogan (1959) entre os Guarani, no Paraguai, tantos outros se agregaram, compondo um amplo e consistente quadro etnográfico, com temas bem delineados. Florestan Fernandes (1949; 1970) consolidou uma síntese ambiciosa da organização social e da função da guerra nos Tupinambá, com base nos relatos de cronistas quinhentistas e seiscentistas. A partir das mesmas fontes, Alfred Métraux (1979; 1927; 1928) já havia abordado em traços vigorosos o sistema religioso, as migrações messiânicas e a cultura material tupiguarani. Egon Schaden (1954) e James Watson (1952) trataram das mudanças culturais (na religião e na economia, respectivamente) entre os Guarani contemporâneos, no centro-sul do Brasil e no Paraguai. Sob um olhar também culturalista, Herbert Baldus (1970) e Charles Wagley (1977) investigaram os Tapirapé, no Mato Grosso, e Charles Wagley e Eduardo Galvão (1961) os Tehetehara (ou Guajajara), no Maranhão. E na mesma região, Francis Huxley (1957) e Darcy Ribeiro (1996) enfocaram aspectos típicos do cotidiano dos Uru- 
bu-Kaapor. Merecem menção, também, o esboço da vida social dos Kayabi, no Mato Grosso, estudados por Georg Grünberg (1970), e a análise da liderança política entre os Parintintin, no rio Madeira, Amazonas, por Waud Kracke (1978).

Simultaneamente, travou-se um acalorado debate acerca do estatuto de um suposto "sistema tupi" de parentesco, classificado inicialmente por Wagley e Galvão (1946) entre os de fusão bifurcada, uma variante sul-americana do tipo então chamado "dakota". Certas divergências de cunho teórico-metodológico repercutem ainda hoje. Primeiro, a disputa entre uma abordagem genealógica e outra categorial, esta última na forma de uma crítica culturalista aos estudos do parentesco. Segundo, a legitimidade de comparações históricas, lingüísticas ou estatísticas entre sistemas de parentesco, normas residenciais e instituições sociais na reconstrução de modelos etnográficos. Por último, a primazia da prerrogativa oblíqua avuncular (tio materno-sobrinha) nas alianças matrimoniais (inegável entre os antigos tupi litorâneos), a sua conjugação, em graus diversos, com trocas simétricas de primos cruzados (em vários grupos hodiernos) e o registro de fórmulas complexas (sem regras positivas de casamento).

Nos anos de 1980, investigações entre grupos indígenas recém contatados na Amazônia setentrional, pautadas por maior rigor etnográfico e ambição analítica, conferiram aos estudos tupiguarani um novo e decisivo impulso. Já então muitos pesquisadores estavam convencidos do fraco rendimento, nas terras baixas sul-americanas, de princípios meramente sociológicos que, em outros recantos, governam o recrutamento e a mobilização de grupos corporados - linhagens, clãs e metades. A hermenêutica estruturalista, cujos enunciados Lévi-Strauss esquadrinhara nas Mythologiques, por sua vez, contribuiu para deslocar o foco da análise, e assim iluminou as relações entre a metafísica da pessoa e seu substrato material, o corpo. Coube a Eduardo Viveiros de Castro (1986), enfim, fundamentar um modelo cosmológico próprio, a partir de uma leitura exaustiva dos materiais tupi-guarani (já iniciada por Pierre Clastres, 1972; e Hèlene Clastres, 1975) e, como é usual em toda a crítica antropológica, nos dados extensos que recolheu entre os Araweté, no Pará. O que se denominou de "economia simbólica da predação", num plano mais geral, busca apreender os fenômenos da guerra e do canibalismo, temas caros aos tupi-guarani, como mecanismos de produção de diferenças sociais por meio de inimigos interpostos. Determinada paradoxalmente pelo seu exterior, a vida social ali se desdobra pela apropriação de identidades e qualidades metafísicas alheias; e a pessoa tupiguarani, em conseqüência, realiza-se segundo uma trajetória centrífuga, como um "devir Outro" - afins, parceiros, inimigos ou deuses, entre outras figuras da alteridade.

Neste retrospecto, ainda que breve, divisamos alguns tópicos que serão retomados por Carlos Fausto em Inimigos fiéis: história, guerra e xamanismo na Amazônia. Originalmente uma tese de doutorado, o livro publicado recebeu o Prêmio Anpocs de 2002, de melhor obra de Ciências Sociais. Seu tema é a vida social e a cultura dos $\mathrm{Pa}$ rakanã, um povo de língua tupi-guarani que habita as bacias do Tocantins e Xingu, no Pará, cuja população de cerca de 800 indivíduos distribui-se em duas áreas demarcadas pela Funai.

A etnografia cuidadosa e instigante - a ponto de o leitor se sentir autorizado, aqui e ali, a ruminar interpretações divergentes das do autor - prossegue na linha investigativa de seus antecessores, não apenas para aferir o rendimento da teoria da "predação canibal", mas decidida a complementá-la. Para o autor, a predação demarca um dos momentos da dialética canibal, enquanto o outro, a familiarização dos inimigos e seus atributos, comportaria a efetiva incorporação de suas capacidades.

O livro divide-se em sete capítulos. De início, a história dos povos indígenas e o processo de colonização regional, que as fontes documentais e as narrativas dos Parakanã sancionam, permite-lhe realçar, na segunda metade do século XIX, dois eventos cruciais, a "descoberta" dos instrumentos de metal (e os gestos rituais para trocálos por jabotis com os "brancos") e a cisão do grupo original em dois ramos, um oriental e outro ocidental, hostis entre si até os contatos promovidos pela Funai na década de 1970 (quando afinal todos sucumbiram "à atração fatal dos presentes 
distribuídos fartamente", p. 90). As diferenças entre um grupo e outro, processadas ao longo de quase um século, proporcionam um reforço metodológico valioso para os argumentos do autor, para quem as formas sociais não se definem como constantes, mas resultam de uma "construção bistórica particular" (p. 175).

O segundo capítulo retrata as derivas na economia e no padrão de assentamento a que chegaram ocidentais e orientais: aqueles, alongando-se nas expedições venatórias, abandonaram as práticas agrícolas e o modo de vida aldeã em favor da dispersão e da beligerância; e estes, em múltiplas aldeias efêmeras, forjaram um compromisso entre a residência coletiva, as roças sazonais e a caça errante. Tais escolhas, de acordo com o autor, engendraram-se pela interação entre dinâmicas internas e forças externas (naturais e sociais).

A mesma questão volta a ser explorada no capítulo seguinte, quanto à morfologia social e à esfera pública: de um lado, a indistinção social e política dos nômades ocidentais; de outro, a segmentação social (grupos patrilineares e metades exogâmicas) e a chefia entre os semi-sedentários orientais. No que diz respeito ao dualismo destes últimos, curva-se o autor à hipótese de uma origem histórica recente: repetidas práticas matrimoniais, em gerações sucessivas (seja relações avunculares, seja entre primos cruzados) teriam suscitado o surgimento das metades exogâmicas, um ordenamento suplementar às regras de casamento - os patrigrupos apyterewa e wyrapina, de um lado; o tapi'pya, do outro. O significado sociológico dessa inovação, contudo, não restou bem esclarecido; e sequer sua singularidade entre as fórmulas duais análogas em outros tupi-guarani, a exemplo dos Parintintin e Tenharim do rio Madeira, Estado do Amazonas.

Dedicado aos temas da inimizade, do canibalismo, da afinidade e das condições para o exercício da guerra, muito extensos para serem aqui tratados, o quarto capítulo destaca o conceito de "consumo produtivo", de talhe marxista. Esgrimindo-o, o autor sinaliza seu afastamento tático de clichês estruturalistas (e maussianos) que, sob a ótica da reciprocidade, consideraram a vingança e a guerra modalidades de troca ou de re- lações simétricas entre inimigos. Para Fausto, a guerra ameríndia recairia na esfera produtiva, e não do consumo. A morte dos inimigos, diz ele, fornece os corpos, os nomes e as identidades, elementos indispensáveis ao processo de estruturação social. Os inimigos, nesses termos, convertem-se em "matéria-prima" a ser despendida na produção das pessoas.

Se a idéia nos é sedutora, não parece menos intrigante a sua invocação no seio da etnologia sul-americana. É verdade que a ênfase com que o autor exaltou as condições materiais e imateriais, sob as quais se diferenciaram os blocos ocidental e oriental, denotava já um certo viés ao gosto do materialismo histórico. Senão como fetiche ou exorcismo, há que se perguntar, qual outra razão metodológica embute-se aqui? Decerto, nenhuma ortodoxia; ao contrário. Pois se para Marx a dialética manifestava, acima de tudo, a forçosa integração do consumo à produção, e vice-versa, a sua leitura na clave antropológica expressa, de imediato, uma ruptura da unidade conceptual original. E com isso, ao apartar a produção do consumo, como se esferas autônomas fossem, a metamorfose metodológica não faz mais que nos devolver, a contragosto, algumas de nossas velhas e conhecidas tipologias (economias do dom etc.).

O autor não advoga, é preciso dizer, qualquer redução dos inimigos e seus atributos à condição plana de objetos ou de insumo, porém, a qualificação positiva de suas capacidades produtivas: a predação, insiste ele, sucede como "uma relação social entre sujeitos" (p. 328). O capítulo seguinte focaliza justamente esta outra face da guerra, localizando-a nos dispositivos xamânicos que, entre os Parakanã, reclamam a interposição de inimigos oníricos, donos de canções, nomes e técnicas terapêuticas. A sintaxe dos sonhos, ali esmiuçada, revela uma função comunicativa entre dois sujeitos, o sonhador e seu interlocutor onírico: este, um inimigo aprisionado e submisso; aquele, um senhor que o domestica como a um xerimbabo. Significa dizer, portanto, que o sonhador e seu parceiro se submetem a uma relação essencialmente assimétrica.

A essa conversão da inimizade em controle e proteção, o autor designa de "predação familiari- 
zante". Forma de adoção que translada a afinidade em consangüinidade; ou, no contexto tupi, que desloca a antinomia sogro-genro (ou tio maternosobrinho) em direção ao eixo vertical da filiação (pai-filho). Na caça, no xamanismo, no ritual e na guerra, o ato predatório culminaria na incorporação e na fusão de uma subjetividade outra, na identificação entre predador e presa: "a vítima não é um pólo meramente passivo, mas fonte de capacidades ao mesmo tempo necessárias e perigosas para a vida social" (p. 417). Com efeito, as canções, principal dádiva dos inimigos oníricos, são representadas como jaguares que, quando cantadas nas festas, cumprem o mesmo destino que os cativos entre os antigos Tupinambá litorâneos, a "morte" ritual no terreiro.

Nos dois últimos capítulos, o autor extrai as conseqüências deste modelo, aplicando-o no contexto dos rituais, dos mitos e das relações com a sociedade nacional, de maneira a reafirmar tanto sua recusa à uma perspectiva de uma "reciprocidade equilibrada", como a sugestão de que a teoria da "economia simbólica da predação" necessitaria, como complemento, de um "modelo das relações assimétricas de controle simbólico".

Nisto, não há motivo de assombro. Tampouco, alguma discordância maior. Afinal, a teoria da predação, sabemos, anunciou-se sempre como assimetria e como descentramento. Mas também porque, com brilho, o autor demonstra sobretudo uma estrita fidelidade à etiqueta avuncular com que os próprios Parakanã costumavam dirigir-se aos estrangeiros: "Que espécie de gente são vocês, meus tios maternos?" (p. 63), assim os interrogavam. Tema ontológico, portanto, sobre o qual, de igual maneira, os tupi-guarani ainda estão a insistir.

\section{BIBLIOGRAFIA}

BALDUS, Herbert. (1970), Tapirapé: tribo tupi do Brasil central. São Paulo, Nacional/Edusp.

CADOGAN, Leon. (1959), Ayvu Rapyta: textos míticos de los Mbyá-Guarani. Boletim 227 (Antropologia, 5), FFLCH, Universidade de São Paulo.
CLASTRES, Hélène. (1975), La terre sans mal: le prophétisme Tupi-Guarani. Paris, Seuil.

CLASTRES, Pierre. (1972), Chronique des indiens Guayaki. Paris, Plon.

FERNANDES, Florestan. (1949), A organização social dos Tupinambá. São Paulo, Instituto Progresso Editorial.

(1970), A função social da guerra na sociedade Tupinambá. São Paulo, Pioneira/Edusp.

GRÜNBERG, Georg. (1970), "Beiträge zur Ethnographie der Kayabi Zentralbrasiliens". Archiv für Völkerkunde, 24: 21-186.

HUXLEY, Francis. (1957), Affable savages: an anthropologist among the Urubu indians of Brazil. Nova York, The Viking Press.

KRACKE, Waud. (1978), Force and persuasion: leadership in an Amazonian society. Chicago/Londres, The University of Chicago Press.

MÉTRAUX, Alfred. (1927), "Les migrations historiques des Tupi-Guarani”. Journal de la Societé des Américanistes, 19: 1-45.

(1928), La civilization matérielle des tribus Tupi-Guarani. Paris, Paul Geuthner.

(1979), A religião dos Tupinambás e suas relações com a das demais tribos tupi-guaranis. 2. ed., São Paulo, Nacional/Edusp (Brasiliana, 267).

NIMUENDAJU, Curt. (1987), As lendas da criação $e$ destruição do mundo como fundamentos da religião dos Apapocúva-Guarani. São Paulo, Hucitec/Edusp.

RIBEIRO, Darcy. (1996), Diários índios: os Urubu-Kaapor. São Paulo, Companhia das Letras.

SCHADEN, Egon. (1954), Aspectos fundamentais da cultura Guarani. Boletim 188 (Antropologia, 4), FFLCH, Universidade de São Paulo. 
VIVEIROS DE CASTRO, Eduardo. (1986), Araweté: os deuses canibais. Rio de Janeiro, Jorge Zahar.

WAGLEY, Charles. (1988), Lágrimas de boas vindas: os indios Tapirapé do Brasil Central. Belo Horizonte/São Paulo, Itatiaia/Edusp (Reconquista do Brasil, 2. série, vol. 137).

WAGLEY, Charles \& GALVÃO, Eduardo . (1946), "O parentesco tupi-guarani". Boletim do Museu Nacional (Antropologia), 6.

(1961). Os indios Tenetehara: uma cultura em transição. Rio de Janeiro, Serviço de Documentação, Ministério da Educação e Cultura.

WATSON, James B. (1952), "Cayua culture change: a study in acculturation and methodology". American Anthropologist, memoir number 73 , v. 54 (2/2).

JOÃO DAL POZ é professor no Departamento de Antropologia da Universidade Federal de Mato Grosso.

\section{Trabalbadores e indústria automobilística em tempos de reestruturação}

Leila BLASS. De volta ao futuro: o discurso empresarial e sindical no fim da Autolatina. São Paulo, Educ/Cortez/Fapesp, 2001. 194 páginas

Marco Aurélio Santana

Nas últimas duas décadas, o mundo do trabalho brasileiro e seus atores, em consonância com o cenário global, enfrentaram diversos processos de transformação. Passando de um período de abertura política, para outro de abertura econômica, empresários e trabalhadores buscaram, a seu modo, lidar com o que seria "um furacão devastador". Entre outras coisas, os empresários, sempre protegidos pelo fechamento da economia nacional, foram obrigados a uma competição agora em escala global; os trabalhadores, sempre o elo mais fraco, sem o impulso inflacionário para suas manifestações, tendo de enfrentar o desemprego em escala geométrica, trocaram as pautas de conquista salarial e de melhores condições de trabalho pelas pautas de manutenção do emprego. No atacado, o que se viu foi o enxugamento de setores e o fechamento de empresas, a liquidação de postos de trabalho e a relativa diminuição tanto do poder do empresariado industrial (substituído em cena pelo financeiro), como do poder sindical no cenário nacional. Acabou-se o tempo em que a FIESP e a CUT eram figuras recorrentes no Jornal Nacional. Empresas e trabalhadores, evidentemente a partir de seus próprios interesses, tiveram de rever suas estratégias de relação entre si e com o mundo.

De volta ao futuro: o discurso empresarial e sindical no fim da Autolatina, de Leila Blass, fruto de sua tese de livre-docência na PUC-SP (1999), traz uma importante contribuição para o entendimento de uma experiência bastante relevante na história do movimento sindical brasileiro entre os anos de 1980 e 1990, bem como da chamada reestruturação produtiva em nosso país. O livro auxilia tanto o leitor especializado, 